\title{
Systolic Anterior Motion Severity
}

National Cancer Institute

\section{Source}

National Cancer Institute. Systolic Anterior Motion Severity. NCI Thesaurus. Code C127594.

The qualitative measurement of the severity of the systolic anterior motion of a cardiac cusp. 